\title{
Chest physiotherapy in cystic fibrosis: a comparative study of autogenic drainage and the active cycle of breathing techniques with postural drainage
}

\author{
S Miller, D O Hall, C B Clayton, R Nelson
}

\begin{abstract}
Background - Autogenic drainage has been suggested as an alternative method of chest physiotherapy in patients with cystic fibrosis. In this study autogenic drainage was compared with the active cycle of breathing techniques (ACBT) together with postural drainage.

Methods - Eighteen patients with cystic fibrosis took part in a randomised two-day crossover trial. There were two sessions of one method of physiotherapy on each day, either autogenic drainage or ACBT. The study days were one week apart. On each day the patients were monitored for six hours. Mucus movement was quantified by a radioaerosol technique. Airway clearance was studied qualitatively using xenon-133 scintigraphic studies at the start and end of each day. Expectorated sputum was collected during and for one hour after each session of physiotherapy. Pulmonary functions tests were performed before and after each session. Oxygen saturation $\left(\mathrm{SaO}_{2}\right)$ and heart rate were measured before, during, and after each session.

Results - Autogenic drainage cleared mucus from the lungs faster than ACBT over the whole day. Both methods improved ventilation, as assessed by the xenon-133 ventilation studies. No overall differences were found in the pulmonary function test results, but more patients had an improved forced expiratory flow from $25 \%$ to $75 \%$ with autogenic drainage, while more showed an improved forced vital capacity with ACBT. No differences were found in sputum weight and heart rate, nor in mean $\mathrm{SaO}_{2}$ over the series, but four patients desaturated during ACBT.

Conclusions - Autogenic drainage was found to be as good as ACBT at clearing mucus in patients with cystic fibrosis and is therefore an effective method of home physiotherapy. Patients with cystic fibrosis should be assessed as to which method suits them best.

(Thorax 1995;50:165-169)
\end{abstract}

Keywords: cystic fibrosis, autogenic drainage, active cycle of breathing techniques, physiotherapy.

Chest physiotherapy in the treatment of cystic fibrosis is long established..$^{1-5}$ The conventional treatment for many years was postural drainage with percussion. Thompson and Thompson in 1968 developed the forced expiration technique to improve the efficiency of secretion removal. ${ }^{6}$ Pryor et al explained the mechanism of this technique using Mead's concept of the equal pressure point ${ }^{78}$ and studied this method combined with postural drainage in patients with cystic fibrosis. ${ }^{9}$ Since the early 1980 s most cystic fibrosis centres in Britain have taught this form of home management for chest clearance. The name of the method has recently been changed to the active cycle of breathing techniques (ACBT).

In recent years new methods of chest clearance have been developed, ${ }^{10}$ among which are positive expiratory pressure mask therapy (PEP), ${ }^{11}$ high pressure PEP, ${ }^{12}$ and autogenic drainage. ${ }^{1314}$

Autogenic drainage was developed by Chevaillier in Belgium. This technique aims to reach the highest possible airflow in the different generations of bronchi to move secretions and does not involve any forced expiration. There has been little research into the effects of autogenic drainage in comparision with other methods, ${ }^{15-17}$ and none comparing it with ACBT.

In chest physiotherapy it has become clear that judging a method by the amount of sputum expectorated is not always correct. Mucus clearance of radiolabelled aerosol gives a picture of where mucus is in the lungs, if it is moving from a particular area, and whether there is any effect on the more peripheral airways. Scintigraphic studies have shown that mucus may be swallowed during and after treatment as it is visible in the stomach, suggesting that measurement of the amount of sputum expectorated can be misleading. ${ }^{18-20}$ It was therefore decided to compare these two methods using lung scintigraphy.

\section{Methods}

The study was carried out to determine whether autogenic drainage, a technique carried out at only $17 \%$ of centres in the UK, was as effective in clearing lung mucus as ACBT, the standard method used at $96 \%$ of centres. ${ }^{10}$ The study also looked for differences between the methods, particularly in the clearance of central and peripheral airways.

\section{PATIENTS}

Eighteen patients (10 men) aged $11-32$ years 
with cystic fibrosis were studied. ShwachmanKulczycki scores, ${ }^{21}$ modified with the ChrispinNorman score, ${ }^{22}$ were between 34 and 87 . All patients were clinically stable at the time of the study and were not receiving intravenous antibiotics. A lower age limit of 11 years was set because of the high degree of patient cooperation necessary. Informed consent, as approved by the hospital ethics committee, was obtained from all patients. ARSAC (Administration of Radioactive Substances Advisory Committee) approval was also obtained for the use of radioactive preparations.

The patients were tested before the study for reversibility to a bronchodilator. If there was a positive response patients received a nebulised bronchodilator before each session of physiotherapy; if there was no response they received nebulised saline.

Each patient was studied over two days one week apart to prevent any carry over effect. On each day the patient performed two sessions of physiotherapy - morning and afternoon. They were all fully trained in both methods, but all had used ACBT for many years before learning autogenic drainage. Patients were asked to be regular with their home physiotherapy in the week leading up to the trial and in the intervening period.

\section{PHYSIOTHERAPY TECHNIQUES}

Before physiotherapy the patients inhaled a pretreatment nebuliser of salbutamol or saline, depending on established reversibility studies. Volumes of $4 \mathrm{ml}$ were nebulised $(2.5 \mathrm{ml}$ salbutamol and $1.5 \mathrm{ml}$ saline, or $4 \mathrm{ml}$ saline) in a Medicaid system 22 nebuliser with a mouthpiece powered by a Medicaid CR60 compressor. This took approximately eight minutes. In accordance with established practice, on the day ACBT was performed the patients were asked to breath normally, while on the day autogenic drainage was performed they did autogenic drainage breathing exercises during inhalation. A 30 minute treatment session then followed. On each day there was a morning and an afternoon session consisting of eight minutes inhalation through the nebuliser and 30 minutes of chest clearance per session. For the purposes of the study we standardised the postural drainage positions so that as much of the lungs as possible would be treated on the ACBT days for comparison with autogenic drainage which is a whole lung treatment. We do not recommend that these same postural drainage positions should be adhered to as a rigid regimen for all patients.

On the day ACBT was performed, postural drainage was performed on a Chesham frame. In the morning session postural drainage positions were adopted to drain the posterior lower lobes, anterior lower lobes, left lower lobes, and right lower lobes, and in the afternoon the left middle lobe, right middle lobe, anterior upper lobe, and apical upper lobe. Each position was held for seven and a half minutes. In each postural drainage position the ACBT was performed several times, commencing with tidal volume breathing with the lower chest (breathing control) for approximately six breaths, followed by 3-4 deep inspirations of full capacity, then another period of breathing control. Finally, the patient performed one or two forced expirations (huffs) from mid to low lung volume. If secretions were felt to be high enough in the proximal airways a huff was performed at a higher lung volume. Patients were encouraged to cough and expectorate only if the secretions were high enough. After the huffs and/or cough a further period of gentle lower chest breathing control was performed, and the cycle repeated. Selfclapping was performed on a limited basis during the deep inspiration phase.

On the day autogenic drainage was performed the patient's position for the treatment was sitting or supine. The posture, if sitting, was upright with the neck slightly extended; if lying it was flat with the arms away from the body and the thorax unrestricted.

The patient began by performing diaphragmatic breathing at a low lung volume. Inspiration was slow with a pause of three seconds, and expiration was done as a sigh with an open glottis and with as high a velocity as possible but no forced expiration. During this low lung volume breathing, expiration was encouraged down to the expiratory reserve volume. When the patient felt secretions to be moving, the volume of inspiration became deeper and the expiration did not go down as far as the expiratory reserve volume. As the secretions moved up the bronchial tree to the large airways the patient performed higher lung volume breathing, tidal volume to inspiratory reserve volume. Only when the secretions were felt to be as high as possible did expectoration occur. The patients were taught to suppress the cough to allow this. The cycle of breathing exercises was repeated throughout the $30 \mathrm{~min}$ ute morning and afternoon treatment sessions.

\section{MEASUREMENTS}

A xenon-133 gas ventilation study was carried out at the start of the day. First breath, equilibrium, and washout pictures were recorded by a gamma camera (Siemens ZLC 7500) linked to a nuclear medicine computer system (Bartec System 3). These images were assessed by a radiologist experienced in both cystic fibrosis and scintigraphy to confirm that the patient's condition was essentially the same on both days, and to group the patients into mild, moderate, and severe disease according to the pattern of xenon distribution in the lungs. From the tenth patient onwards the ventilation study was repeated at the end of both days to look for changes in lung ventilation due to the treatment. $^{23}$

Pulmonary function tests were carried out using a spirometer (Vitalograph Alpha) which was calibrated daily. Vital capacity (VC), forced vital capacity (FVC), forced expiratory volume in one second $\left(\mathrm{FEV}_{1}\right)$, peak expiratory flow (PEF), and forced expiratory flow from 25$75 \%\left(\mathrm{FEF}_{25-75}\right)$ were recorded at the beginning of the day and before and after each session of chest clearance. Oxygen saturation levels 
$\left(\mathrm{SaO}_{2}\right)$ and heart rate were recorded during each treatment session using a Nellcor pulse oximeter, and resting levels were recorded before and after.

After the ventilation study, pulmonary function tests, $\mathrm{SaO}_{2}$, and heart rate recordings had been performed, the patient inhaled human serum albumin aerosol labelled with technetium-99m (Solco Venticoll supplied by Incstar). A Medicaid System 22 Optimist nebuliser powered by a Medicaid CR60 air compressor delivered the aerosol. The aerosol particles had a mass median diameter of $0.9 \mu \mathrm{m}$ and a geometric standard deviation of $1.4 \mu \mathrm{m} .^{24}$

The patients inhaled the aerosol via a mouthpiece while wearing a noseclip and sitting upright. They were asked to breath normally and, approximately every 10 breaths, to breath in slowly and deeply and hold their breath for three seconds. ${ }^{25}$ The inhalation time was 20 minutes. At the start of each session a static posterior image of the distribution of the radiolabelled aerosol in the lungs was acquired for 150 seconds on the gamma camera with the patient sitting. Dynamic images were taken during the physiotherapy. Further static posterior images were recorded immediately after the end of each session and about one hour later (the exact time varied according to camera availability).

The static images were corrected for background and radioactive decay, and regions of interest were drawn over the right and left lungs to measure retained activity. The equilibrium ventilation images were used to draw the lung outlines and to designate a central and peripheral lung region. Using a single compartment model, clearance was assumed to be exponential. A value of percentage change per hour was calculated for each region using a least squares fit to the log of the counts, corrected for radioactivity decay. The time of the first view was taken to be time zero. For each patient the proportional difference between the rates of change on the two days was calculated.

Sputum was collected in a preweighed pot during the nebuliser and treatment period. It was weighed immediately after treatment. Sputum was then collected for a further hour and weighed again.

A visual analogue score to assess patient preference between autogenic drainage and ACBT was performed at the end of the second day. Patients were also asked to give two reasons for their preference.

\section{DATA ANALYSIS}

The study was analysed using the method outlined by Hills and Armitage for a two period crossover clinical trial. ${ }^{26}$ Carry over between the two study periods was tested for but found not to be significant. Differences between the two methods were tested using the paired $t$ test.

\section{Results}

OXYGEN SATURATION LEVELS

There was no difference in mean $\mathrm{SaO}_{2}$ between the methods over the study days. However, four patients with moderate to severe disease desaturated during the morning ACBT session, and one of these patients also desaturated in the afternoon ACBT session. No patients desaturated during any autogenic drainage session.

\section{HEART RATE}

The change in heart rate from the value measured just before treatment to the average value during and immediately after treatment was calculated for each patient. The results were not clinically significant.

\section{PATIENT PREFERENCE}

Nine patients preferred autogenic drainage, eight preferred ACBT, and one patient had no preference.

\section{PULMONARY FUNCTION TESTS}

Taken overall, pulmonary function tests showed no significant difference between the two methods. However, more patients had an improved $\mathrm{FEF}_{25-75}$ on autogenic drainage than on ACBT, while the converse was true for FVC (table 1).

\section{SPUTUM WEIGHTS}

Sputum was collected and weighed during and for up to one hour after each physiotherapy session. The average weight in one day was 23 (range 2-105) g. The mean (SE) difference between autogenic drainage and ACBT was not significant $(-0.4(1 \cdot 8) \mathrm{g})$. No correlation was found with the results of radiolabelled aerosol clearance, in agreement with reports in the literature. ${ }^{19}$

\section{VENTILATION STUDIES}

Using the intitial ${ }^{133} \mathrm{Xe}$ ventilation study, lung condition was found to be mildly affected in six cases, moderately affected in seven, and severely affected in five patients. The assessments did not change between study days. The last nine patients (three mild, three moderate, and three severe) had repeat ventilation studies performed at the end of the day. More uniform or more widely distributed xenon gas on first breath or increased washout rate were regarded as improvements. Examples of two pairs of first breath studies from the start and

Table 1 Number of tests out of 36 (18 morning and 18 afternoon) which showed an improvement of $>10 \%$, $>15 \%$, and $>20 \%$ for forced expiratory flow from $25 \%$ to $>15 \%$, and $>20 \%$ for forced expiratory flow from
$75 \%\left(F E F_{25-75}\right)$ and forced vital capacity (FVC)

\begin{tabular}{|c|c|c|c|c|}
\hline \multirow[t]{2}{*}{$\begin{array}{l}\text { Percentage } \\
\text { improvement }\end{array}$} & \multicolumn{2}{|c|}{$F E F_{25-75}$} & \multicolumn{2}{|l|}{$F V C$} \\
\hline & $A C B T$ & $\begin{array}{l}\text { Autogenic } \\
\text { drainage }\end{array}$ & $A C B T$ & $\begin{array}{l}\text { Autogenic } \\
\text { drainage }\end{array}$ \\
\hline $\begin{array}{l}>10 \% \\
>15 \% \\
>20 \%\end{array}$ & $\begin{array}{r}10 \\
8 \\
7\end{array}$ & $\begin{array}{r}17 \\
11 \\
9\end{array}$ & $\begin{array}{r}17 \\
11 \\
8\end{array}$ & $\begin{array}{r}15 \\
10 \\
4\end{array}$ \\
\hline
\end{tabular}

ACBT $=$ active cycle of breathing techniques. 


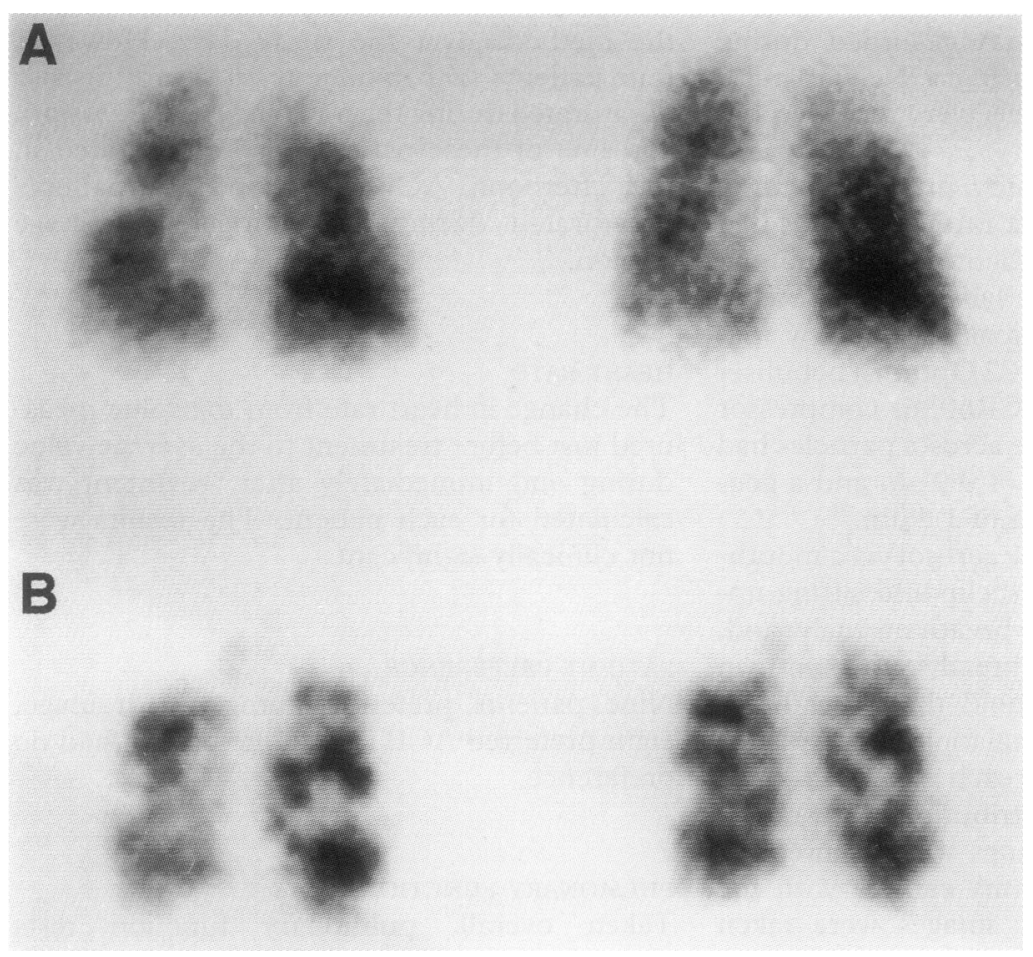

First breath studies from the start (left) and end (right) of the day. (A) Patient with moderate disease, showing improvement at the end of the day. (B) Patient with severe disease, showing no improvement. end of the day are shown in the figure. Dark areas show the presence of xenon gas. The first patient (A) had moderate lung disease and showed improvement at the end of the day. The second patient (B) had severe lung disease and showed no improvement.

All three of the moderate patients, and one each of the mild and severe patients, showed improvements for both methods of physiotherapy on first breath, while the other four showed no improvement. On washout, six cleared faster and three cleared slower on autogenic drainage, while with ACBT four cleared faster, three slower, and two did not change.

\section{CLEARANCE OF RADIOLABELLED AEROSOL}

The clearance rates and the proportional differences between the two methods over the whole day are given, grouped according to lung region for all patients and disease severity for the whole lungs (table 2). Clearance rates were faster with autogenic drainage than with ACBT for whole lung and central lung regions, but

Table 2 Average clearance rates for autogenic drainage and ACBT over the whole day for all 18 patients grouped according to lung region, and for the whole lungs grouped according to disease severity, and proportional differences in rates

\begin{tabular}{|c|c|c|c|c|c|}
\hline & $n$ & $\begin{array}{l}\text { Mean }(S D) \\
\text { clearance } \\
\text { rate with } \\
A C B T \\
\text { (\%/hour) }\end{array}$ & $\begin{array}{l}\text { Mean }(S D) \\
\text { clearance } \\
\text { rate with } \\
\text { AD } \\
\text { (\%/hour) }\end{array}$ & $\begin{array}{l}\text { Mean (SE) } \\
\text { proportional } \\
\text { difference }\end{array}$ & $p$ \\
\hline \multicolumn{6}{|l|}{ Lung region } \\
\hline Whole lung & 18 & $3 \cdot 2(1 \cdot 4)$ & $3.9(1 \cdot 4)$ & $0.22(0.09)$ & $<0.05$ \\
\hline Central & 18 & $2 \cdot 9(1 \cdot 3)$ & $3 \cdot 6(1.4)$ & $0 \cdot 25(0 \cdot 10)$ & $<0.05$ \\
\hline Peripheral & 18 & $4 \cdot 7(2 \cdot 0)$ & $5 \cdot 5(2 \cdot 2)$ & $0 \cdot 19(0 \cdot 12)$ & NS \\
\hline \multicolumn{6}{|l|}{ Disease severity } \\
\hline Mild & 6 & $2 \cdot 7(1 \cdot 2)$ & $3 \cdot 8(2 \cdot 0)$ & $0 \cdot 35(0 \cdot 19)$ & NS \\
\hline Moderate & 7 & $2 \cdot 8(1 \cdot 0)$ & $3 \cdot 3(0.3)$ & $0 \cdot 21(0 \cdot 13)$ & NS \\
\hline Severe & 5 & $4 \cdot 3(1 \cdot 5)$ & $4 \cdot 7(1 \cdot 3)$ & $0 \cdot 10(0 \cdot 23)$ & NS \\
\hline
\end{tabular}

Proportional difference is expressed as $(1 / n) \Sigma 2(\mathrm{AD}-\mathrm{ACBT}) /(\mathrm{AD}+\mathrm{ACBT})$, where $\mathrm{AD}$ and ACBT are the rates of clearance for individual patients, and $n$ is the number of patients in each group. $\mathrm{ACBT}=$ active cycle of breathing techniques; $\mathrm{AD}=$ autogenic drainage. not significantly different for the lung periphery. Dividing the patients according to disease severity makes the number in each group very small and therefore impossible to analyse statistically. However, any differences are most apparent in the mild and moderate categories.

The dynamic images were not used in the quantitative analysis. Inspection of these images showed activity appearing in the stomach, but no major shifts of activity between regions of the lungs.

\section{Discussion}

Some workers have found falls in $\mathrm{SaO}_{2}$ due to postural drainage and percussion in patients with cystic fibrosis, ${ }^{11}$ while others have not found such a fall when breathing control rests are included. ${ }^{27}$ In our results falls in $\mathrm{SaO}_{2}$ were found during ACBT with postural drainage despite our inclusion of breathing control, but these did not show in the mean $\mathrm{SaO}_{2}$ results which may explain some of the disagreement in the literature.

The patients who preferred autogenic drainage to ACBT (nine of 18) tended to be those with better concentration who were generally more compliant with treatment. The concentration needed to perform autogenic drainage is an important factor in deciding whether to advise autogenic drainage as a method of choice. The time taken to learn autogenic drainage is much longer than the time needed to learn ACBT. In general, younger patients may lack the necessary concentration.

Pulmonary function tests were performed initially before the inhalation of radiolabelled aerosol, and then after physiotherapy. It was noted that pulmonary function decreased by an excessive amount after the morning sessions in two of the first three patients. Therefore, from the fourth patient onwards the pulmonary function tests were repeated after inhalation of the aerosol. This showed an adverse effect in a further seven patients, probably due to bronchoconstriction. This effect rapidly disappeared but we felt that, where this occurred, pulmonary function tests after physiotherapy were worse than they would have been otherwise. This should be noted for further research using inhaled radiolabelled aerosols since there may be an adverse effect on deposition.

Repeat ventilation studies showed two types of change. Improvements in first breath images showed areas of the lungs which had been cleared of mucus or where bronchoconstriction had decreased. Conversely, new deficits showed either that mucus had moved into an area of the lung or that bronchoconstriction was affecting that area. The changes in washout rates indicated whether airflow and lung compliance had got better or worse.

De Cesare et $a l^{23}$ studied nine patients with cystic fibrosis using krypton-81m ventilation studies (equivalent to ${ }^{133} \mathrm{Xe}$ first breath studies) and found no improvements in three patients with mild disease, improvements in three patients with severe disease, and changes independent of treatment for three patients with moderate disease. We cannot say whether the 
changes found in our study were independent of treatment, although we were looking for definite improvements in regional ventilation rather than simply changes. The one patient in our study assessed as mild on first breath, and who showed improvements, expectorated more than $50 \mathrm{~g}$ of mucus during each day. The improvement in the ventilation in this case was increased uniformity of gas distribution rather than the clearance of blocked areas.

The ventilation studies indicated that both methods of physiotherapy are effective at clearing lung obstruction caused by mucus.

Aerosol deposition in severe disease is predominantly in the central airways, whereas for mild disease there is better peripheral deposition. The information gained about clearance is more reliable when deposition is good than when it is poor. As a consequence, proportional differences in clearance are likely to be more reliable for central lung regions, for the whole lungs, and for patients with mild disease.

In conclusion, the results showed increased rates of clearance of mucus on the days when autogenic drainage was performed. There was no overall difference in sputum weights. Both methods proved able to clear lung obstructions, shown by scintigraphic ventilation studies. Pulmonary function tests showed no overall difference between the methods, but showed that autogenic drainage improved $\mathrm{FEV}_{25-75}$ more often than ACBT, while the converse was true for FVC. The patients were found to have similar oxygen saturation levels for both methods, but the ACBT caused desaturation in some cases. Heart rate changes were not clinically significant. Overall, patients liked both methods equally.

We are grateful to $\mathrm{Dr} R$ Lee, consultant radiologist, and to $\mathrm{Dr}$ J Matthews, medical statistician, for their invaluable guidance and help during this study. We would also like to thank the clinical medical physics technologists, the physiotherapy department, and particularly the patients who participated, for their time and energy. The Optimist nebulisers were provided by MedicAid.

1 Cochrane GM, Webber BA, Clarke SW. Effects of sputum on pulmonary function. BMF 1977;2:1181.

2 Feldman J, Traver GA, Tuassig LM. Maximal expiratory flows after postural drainage. Am Rev Respir Dis 1979; 119:239-45.

3 Levison HL, Godfrey S. Pulmonary aspects of cystic fibrosis. In: Mangos JA, Talamo RC, eds. Cystic fibrosis, projections into the future. New York: Stratton, 1976:3-24.

4 Lorin MI, Denning CR. Evaluation of postural drainage by measurement of sputum

5 Maxwell M, Redmond A. Comparative trial of manual and mechanical percussion techniques with gravity assisted mechanical percussion techiques with cysic fibrosis. Dis Child 1979;54:542-4.

6 Thompson B, Thompson HT. Forced expiration exercises in asthma and their effect on $\mathrm{FEV}_{1}$. NZ $\Im$ Physiother 1968; 3:19-21.

7 Pryor JA, Webber BA, Hodson ME, Batten JC. Evaluation of the forced expiration technique as an adjunct to postural drainage in the treatment of cystic fibrosis. $B M \mathcal{F} 1979 ; 2$ : 417-8.

8 Mead J, Turner JM, Macklem PT, Little JB. Significance of the relationship between lung recoil and maximum expiratory flow. F Appl Physiol 1967;22:95-108.

9 Pryor JA, Webber BA. An evaluation of the forced expiratory technique as an adjunct to postural drainage. Physiotherapy 1979;65:304-7.

10 Prasad SA. Current concepts in physiotherapy. $f R$ Soc Med 1993;86(Suppl 20):23-9.

11 Falk M, Kelstrup M, Anderson JB, Kinoshita T, Falk P, Stovring $\mathrm{S}$, et al. Improving the ketchup bottle method with positive expiratory pressure PEP in cystic fibrosis. Eur f Respir Dis 1984;65:423-32.

12 Oberwaldner B, Evans JC, Zach MS. Forced expirations against a variable resistance: a new chest physiotherapy method in cystic fibrosis. Pediatr Pulmonol 1986;2:358-67.

13 Schoni MH. Autogenic drainage: a modern approach to physiotherapy in cystic fibrosis. $\mathcal{F} R$ Soc Med 1989; 82(Suppl 16):32-7.

14 Chevaillier J. Autogenic drainage (AD). In: Lawson D, ed. Cystic fibrosis: horizons. Chichester: John Wiley, 1984:235.

15 McIlwaine M, Davidson AGF, Wong LTK, Pirie GE, Nakielna EM. Comparison of positive expiratory pressure and autogenic drainage with conventional percussion and drainage therapy in the treatment of cystic fibrosis. Asia Pacific Congress Series, 10th International Cystic Fibrosis Congress, Sydney. Excerpta Medica, 1988:120.

16 Mcllwaine PM, Wong LTK, Pirie GE, Davidson AGF. Long term comparative trial of conventional percussion and drainage versus autogenic drainage in cystic fibrosis. XIth International CF Congress Book of Abstracts, Dublin 1992: Allied Health Professionals No. 32 (abstract).

17 Pfleger A, Theissl B, Oberwaldner B, Zach MS. Self administered chest physiotherapy in cystic fibrosis: a comparative study of high pressure PEP and autogenic parative study of high pressure
drainage. Lung 1992;170:323-30.

18 Rossman CM, Waldes R, Sampson D, Newhouse MT. Effect of chest physiotherapy on the removal of mucus in patients with cystic fibrosis. Am Rev Respir Dis 1982; 126:131-5.

19 Mortensen J, Falk M, Groth S, Jensen C. The effects of postural drainage and positive expiratory pressure physiotherapy on tracheobronchial clearance in cystic fibrosis. Chest 1991;100:1350-7.

20 Isawa $T$, Teshima $T$, Hirano $T$, Ebina A, Motomiya $M$, Konno K. Lung clearance mechanisms in obstructive airways disease. 7 Nucl Med 1984;25:447-54.

21 Shwachman H, Kulczycki LL. Long-term study of one hundred and five patients with cystic fibrosis. Am $\mathcal{F} \mathrm{Dis}$ hundred and five patie

22 Chrispin AR, Norman AP. The systematic evaluation of the chest radiograph in cystic fibrosis. Pediatr Radiol 1974;2: 101-6.

23 De Cesare JA, Babchyck BM, Colten HR, Treves S. Radionuclide assessment of the effects of chest physical therapy on ventilation in cystic fibrosis. Phys Ther 1982;62:820-5.

24 O'Doherty MJ, Miller RF. Aerosols for therapy and diagnosis. Eur F Nucl Med 1993;20:1201-13.

25 Clarke SW, Pavia D. Aerosols and the lungs. London: Butterworths, 1984:49-70.

26 Hills M, Armitage P. The two-period cross-over clinical trial. Br $₹$ Clin Pharmacol 1979;8:7-20.

27 Pryor JA, Webber BA, Hodson ME. Effects of chest physiotherapy on oxygen saturation in patients with cystic fibrosis. Thorax 1990;45:77.

tx94-187 